\title{
Complement-Targeted Therapies in Lupus
}

\section{Gary S. Gilkeson, M.D. ${ }^{1,2, *}$}

\author{
Address \\ ${ }^{*}, 1$ Department of Medicine, Medical University of South Carolina, 96 Jonathan \\ Lucas Street, Suite 816, MSC 637, Charleston, SC 29425, USA \\ Email: Gilkeson@musc.edu \\ ${ }^{2}$ Medical Research Service, Ralph H. Johnson VAMC, Charleston, SC, USA
}

Published online: 22 January 2015

(C) Springer International Publishing AG 2015

This article is part of the Topical Collection on Lupus

Keywords Complement therapies - Systemic lupus - Lupus nephritis - Targeted therapies - Lupus animal models . Complement inhibitors

\section{Opinion statement}

Systemic lupus erythematosus is a complex disease affecting most organs in the body. Deficiency of early components of the classical complement pathway is a key predisposing genetic factor for lupus in both mice and humans. Activation of the complement cascade downstream of $\mathrm{C} 3$ is a key factor in tissue inflammation and damage in lupus. Thus, lupus provides an interesting puzzle for how and when to block complement activation as a therapy. Interventions blocking $\mathrm{C}_{5}$, the alternative pathway, the lectin pathway, and the terminal membrane attack complex are all effective in treating murine models of lupus. Over 20 complement-directed therapies are in clinical trials for various diseases. Despite the promising results regarding efficacy of complement inhibition in murine lupus, the overall lack of effective therapies in lupus, and the availability of a number of complement inhibitors for human trials, there have been and currently are no trials of complement inhibitors for treating lupus. The complexity of lupus and the failure of many recent clinical trials in lupus have perhaps discouraged industry sponsors from testing their complement therapies in lupus. There may also be concern that blocking complement alone may not be effective in treating lupus as other inflammatory mediators are also involved in disease pathogenesis. Despite these possible confounders, it is clear that complement is a key mediator of tissue inflammation and damage in lupus. Complement inhibitors may not be effective at long-term chronic management of lupus, but would appear to be very attractive as an acute intervention during disease flares, especially in lupus nephritis. Ongoing efforts by the NIH and by the lupus organizations to bring new lupus drugs to patients will hopefully lead to clinical trials of complement inhibitors in lupus in the near future. 


\section{Introduction}

Systemic lupus erythematosus is a complex disease characterized by autoantibody production, immune complex formation, complement activation, and tissue damage [1]. Almost all organs in the body are affected by lupus, though the specific organs involved vary widely from patient to patient. C3 deposition in target organs, as well as evidence of local complement production in target organs, has led to a significant research effort focused on understanding the role of complement in disease and in developing therapeutics to block complement-mediated tissue damage [2].
The complement system is a complex set of enzymes with activation occurring through three different pathways, the classical, the alternative, and the lection pathways $[3,4]$. All three converge at C3, but each has different roles in health and disease and each has different mechanisms of activation. Once the pathways converge at $\mathrm{C} 3$, the downstream terminal components of the pathways are the same with generation of $\mathrm{C} 3 \mathrm{a}$ and $\mathrm{C} 3 \mathrm{~b}, \mathrm{C} 5 \mathrm{a}$ and $\mathrm{C} 5 \mathrm{~b}$ ending with the formation of the membrane attack complex [4]. Significant research has examined the relative role of each pathway in lupus and which factors downstream of C3 are key for disease expression [3, 5].

\section{Complement and lupus}

Complement is known to have a dichotomous role in lupus, further complicating efforts to define the best therapeutic approach for blocking complement in lupus. Deficiency of early components of the classical complement pathway, i.e., $\mathrm{C} 1 \mathrm{q}, \mathrm{C} 2$, and $\mathrm{C} 4$, are associated with a high risk of developing lupus [6, 7]. Indeed, penetrance of disease expression for $\mathrm{C} 1 \mathrm{q}$ and $\mathrm{C} 2$ expression is the highest identified genetic risk for lupus [8]. Understanding the mechanisms for the development of lupus in early complement factor deficiencies provides insight into the pathogenesis of lupus [9]. The lack of these complement factors decreases clearance of immune complexes and delays clearance of apoptotic debris. These defective clearance mechanisms result in increased immune complex deposition and higher levels/longer exposure of the immune system to self-antigens [6]. Other genetic deficiencies that result in poor clearance of apoptotic debris (i.e., DNAse I and TREX1) also are associated with increased risk of lupus [10-14]. Thus, complete inhibition of the complement pathway, especially early in the pathway, would likely be deleterious in lupus [6].

In contrast, complement activation in target tissues is clearly associated with tissue damage. Immune complex and complement deposition is the hallmark pathologically of lupus nephritis. C1q, C3, C4, factor B (FB), factor D (FD), and the membrane attack complex (MAC) can all be readily detectable in patients with active lupus nephritis $[15,16]$. Immune complexes form via one of three mechanisms. First, immune complexes may preform in the serum and then be deposited in the kidney. Second, DNA/histones and other targets of autoantibodies are deposited in the glomerulus due to charge interactions then resulting in complement activation. Finally, there may be cross-reactivity of some lupus autoantibodies with intrinsic glomerular antigens also leading to complement activation $[15,17]$. Once activated, there is continued and increasing complement activation through the alternative pathway amplification loop [18]. C3a and C5a attract inflammatory cells to the kidney and result in production of additional inflammatory cytokines and mediators [19-22]. Formation of the MAC leads to tissue/cell damage in the kidney [23-26]. Although most 
attention has previously focused on the glomerulus, there is also recent compelling evidence that there is a significant role for complement activation in tubular damage in lupus $[25,26]$. This is partly due to tubular cells lacking complement inhibitory factors on the urinary side of the cell allowing damage to occur via complement products in the urine $[25,26]$. Tubular damage is increasingly being recognized as a key factor in progression to ESRD. Of possible relevance to lupus is recent insight from studies of complement in ischemia reperfusion injury. Although inhibiting the complement pathway results in initial decrease in ischemic damage, long-term outcome is worse. However, blocking only the MAC results in significant improvement in outcome [27]. These findings indicate that most of the damage by complement is due to the MAC, while the generation of $\mathrm{C} 3 \mathrm{a}$ and $\mathrm{C} 5 \mathrm{a}$ are critical for attracting inflammatory cells/stem cells to clear necrotic debris and allow regeneration [27]. This phenomenon has not been demonstrated in lupus nephritis, but points out the need to fully understand pathogenic mechanisms and tailor complement therapies to the key pathogenic factors in each disease.

Lupus nephritis is not the only manifestation of lupus that is complement mediated. MRL/lpr mice are a strain that spontaneously develops lupus nephritis and lupus cerebritis. MRL/lpr mice treated with a complement inhibitor demonstrated less severe brain inflammation compared to wild type mice and resulting in improved performance in cognitive testing [28]. MRL/lpr mice also develop significant lupus like skin disease; however, factor B neither factor D nor C3 deficiency resulted in improvement in skin disease [29, 30]. CR2FH and CR2Crry given systemically did lead to decreased inflammatory lung disease in these mice [31]. Thus, it is likely that complement inhibition may be effective in some manifestations of lupus, but not all.

Due to the complexity of the complement system, its multiple pathways, its multiple components, and its multiple inhibitors, a number of therapeutic approaches exist and are being tested in lupus. Unfortunately to date, there have been no reported trials of successful use of a complement inhibitor in human lupus, although a couple of case reports suggest efficacy [32,33].

\section{Complement-related therapies in lupus}

Preclinical animal studies to date suggest that the alternative complement pathway and the terminal pathway downstream of $\mathrm{C} 3$ activation are the most attractive targets. These studies involved use of complement factor knockout mice and also therapeutic agents targeting specific components of the complement pathways. In lupus mice lacking factor B and factor D, there was a significant decrease in lupus disease activity primarily manifested as decreased severity of renal disease [34, 35]. Lupus mice lacking C3, however, had increased immune complex deposition in their kidneys and increased renal disease severity [30]. Further evidence for a role of the alternative complement pathway is provided by factor $\mathrm{H}$ knockout mice that had accelerated disease compared to wild type mice [16]. Properdin deficiency has not been studied in lupus, but resulted in less severe joint involvement in arthritis models while paradoxically, properdin deficiency led to worse induced glomerulonephritis $[36,37]$. 
Strategies to block the alternative complement pathway can occur via inhibiting either factor B or factor D activity, versus increasing factor $\mathrm{H}$ activity. Blocking antibodies to factor $\mathrm{B}$ and $\mathrm{D}$ were given to animal models of various inflammatory diseases. Both murine and human trials of blocking factor B or factor D systemically, using antibodies, have overall not been a successful strategy. To summarize, antibody blockade of factor B and factor D can be attained as a short-term strategy but is more difficult to maintain chronically [2]. Chronic inhibition of factor D or factor B is difficult to attain due to an apparent feedback mechanism leading to a heightened compensatory production that overcomes chronic blockade efforts [38].

Significant success was obtained using inhibitors of the alternative pathway including systemic administration of Crry and targeted strategies using CR2Crry and CR2factor $\mathrm{H}[31,39]$. Other targeting strategies using antibodies to hone to sites of inflammation have also been used successfully. In lupus mouse models, CR2factor $\mathrm{H}$ was highly effective in treating spontaneous mouse models of lupus [29]. CR2Crry was also effective but there is no human analog of CR2Crry, though there is overlap of function with human CR1 [31]. Use of these targeting strategies also led to less systemic immune inhibition and less susceptibility to infection compared to systemic inhibition [31].

Antibody inhibitors of $\mathrm{C} 5$ activity with the antibody targeting either C5, C5a, or C5aR were also effective in treating murine models of lupus [40-42]. It is unclear if one of these strategies is superior to the other as they have not been compared head to head. Small molecule inhibitors of C5a and C3a also appear to have efficacy in treating inflammatory diseases including lupus [41].

Further downstream inhibitors of the membrane attack complex are also of potential therapeutic use. Increasing CD59 activity, an inhibitor of the membrane attack complex versus antibodies to one of the members of the membrane attack complex, is also of potential effect [27]. At this time in lupus, it is not clear whether it is the inflammatory mediators $\mathrm{C} 3 \mathrm{a} / \mathrm{C} 5 \mathrm{a}$ versus the membrane attack complex that plays a bigger role in tissue damage in lupus nephritis [15].

\section{Lack of lupus trials testing complement inhibitors}

Despite the clear evidence of a pathogenic role of complement in a number of diseases, there are only two drugs that are FDA approved for the treatment of human disease. One is eculizumab, an inhibitor of C5 [40]. It is approved to treat paroxysmal nocturnal hemoglobinuria and atypical hemolytic uremic syndrome. Although it is effective in mouse models of lupus, it has never been tested in human lupus other than a single case report [32]. It is in clinical trials for a number of other diseases, but not lupus at this time. Another anti-C5 antibody was shown to enhance survival in patients postcoronary artery bypass, but this drug has also not been tested in lupus [43]. The only other complement agents approved in human disease are $\mathrm{C} 1$ inhibitors for treating angioedema. These drugs would not be predicted to be effective in lupus [44].

One reason why there are no ongoing trials of complement therapies in lupus is that a more attractive target has emerged. The most active area of complement research therapeutics at this time is in the treatment of macular degeneration, which is clearly linked to factor $\mathrm{H}$ and complement activity. There 
are a number of clinical trials of various complement therapies for treating AMD in progress [45-47].

As shown in Table 1 derived from ClinicalTrials.gov, there are ongoing trials of complement therapies in sepsis, vasculitis, ischemia reperfusion injury, and transplants, among others. Most of these are therapies targeting C5, C5a, or $\mathrm{C} 5 \mathrm{aR}$. Anti-factor $\mathrm{D}$ and factor $\mathrm{H}$ are in trials for macular degeneration. There are no complement-related therapies listed on ClinicalTrials.gov that are being tested in lupus at this time.

There are a number of drugs that have effects on complement factors and/or complement activation. I am not including in this list drugs that may modulate the complement system, but it is not the primary target. Heparin is one such drug that as shown by the Salmon group, has significant effects on complement activation. This is the primary mode of action by which heparin and related products improve fetal survival in induced anti-phospholipid syndrome in mice and may explain the efficacy of heparin in human anti-phospholipid syndrome induced spontaneous abortions $[48,49]$. Due to the obvious concerns regarding testing agents in pregnancy, there are no trials currently ongoing

Table 1. Complement inhibitors of possible efficacy in lupus, the company developing each drug, their primary targets, and the stage of development/current indication being tested in clinical trials

$\begin{array}{llll}\text { Drug name } & \text { Company } & \text { Target } & \text { Stage of development } \\ \text { Nafamostate } & \text { Torii/SK } & \text { C1s/FD } & \text { Phase III/IV pancreatitis, ATN } \\ \text { FCFD4514s } & \text { Genentech } & \text { FD } & \text { Phase II in AMD } \\ \text { TA106 } & \text { Alexion } & \text { FB } & \text { Preclinical } \\ \text { Bikaciomab } & \text { Novelmed } & \text { FB } & \text { Preclinical } \\ \text { NM9401 } & \text { Novelmed } & \text { Properdin } & \text { Preclinical } \\ \text { HC3-1496 } & \text { InCode } & \text { C3 } & \text { Preclinical ischemia reperfusion } \\ \text { Compstatin } & \text { Potentia/Alcon } & \text { Multiple } & \text { Phase I AMD } \\ \text { sCR1 } & \text { Celldex } & \text { C3-conv/C4b/C3b } & \text { Phase II post CABG } \\ \text { TT30 (CR2FH) } & \text { Alexion } & \text { C3-conv/C3b } & \text { Phase I PNH } \\ \text { Mini-FH } & \text { Amyndas } & \text { C3-conv/C3b } & \text { Preclinical AMD } \\ \text { Amy301 } & \text { Amyndas } & \text { FH recruitment } & \text { Preclinical } \\ \text { Recombinant FH } & \text { Alexion } & \text { C3-conv/C3b } & \text { Preclinical } \\ \text { Eculizumab } & \text { Alexion } & \text { C5 } & \text { PNH/aHUS; phase II kidney transplant, } \\ & & & \text { AMD, Guillain-Barre, MPGN, ITP, APS } \\ \text { Pexelizumab } & \text { Alexion } & \text { C5 } & \text { Phase III post-CABG } \\ \text { Mubodina } & \text { Adienne } & \text { C5 } & \text { Preclinical } \\ \text { Ergidina } & \text { Adienne } & \text { C5 } & \text { Preclinical } \\ \text { ARC1905 } & \text { Ophthotech } & \text { C5 } & \text { Phase I in AMD } \\ \text { LFG316 } & \text { Novartis } & \text { C5 } & \text { Phase II in AMD } \\ \text { MEDI7814 } & \text { MedImmune AstraZeneca } & \text { C5/C5a } & \text { Phase I in COPD } \\ \text { NOX-D19 } & \text { Noxxon } & \text { C5a } & \text { Preclinical sepsis } \\ \text { IFX-1 } & \text { InflaRx } & \text { C5a } & \text { Preclinical sepsis } \\ \text { CCX168 } & \text { ChemoCentryx } & \text { C5aR } & \text { Phase II in ANCA vasculitis } \\ \text { PMX53 } & \text { Teva } & \text { C5aR } & \text { Phase II in RA- ineffective } \\ \text { ADC-1004 } & \text { Alligator } & \text { C5aR } & \text { Preclinical ischemia reperfusion } \\ \text { NN8209 } & \text { Novo Nordisk } & \text { C5aR } & \text { Phase II in RA- ? Completed } \\ \text { NN8210 } & \text { Novo Nordisk } & \text { C5aR } & \text { Phase I in SLE- ? Abandoned } \\ \text { Imprime PGG } & \text { Biothera } & \text { CR3 } & \text { Phase I-III in cancer } \\ & & & \end{array}$


regarding complement therapies and APL in pregnancy. There is one preclinical effort listed to test eculizumab in catastrophic APL based on a case report [33].

\section{Summary}

Given the clear data that the complement system is pathogenic in lupus and there are a number of potential agents to test for efficacy in lupus, the question arises as to why there are no trials of these multiple complement-targeted therapies in lupus. There is no one answer to this question. One potential reason is that lupus nephritis would be the type of lupus most likely to be studied. Given the multiple negative trials of novel agents to treat lupus nephritis, pharmaceutical companies may be reluctant to spend the millions of dollars required for such a trial until a clear trial design strategy is developed that can differentiate effective therapy from current standard of care treatment [50, 51]. It is also clear from studies of Fc receptors that Fc receptors also play a key role in human and murine lupus nephritis [52]. Thus, there is a valid concern that inhibiting complement activation alone may not be sufficient to see a clear effect over all the background medications that lupus nephritis patients are given. Combination therapy is likely going to be required. It was also shown, as noted above, to be difficult to effectively block the alternative pathway over extended periods. Thus, one might envision that complement blockade would be an adjunct therapy given at the time of acute active disease, but not be a mainstay of therapy. Unfortunately, unless one of these agents is tried in lupus, we will not know how effective or ineffective they are.

Another factor limiting use of these agents in lupus nephritis is the corporate strategy of companies developing complement-targeted therapies. One company that has the rights to develop a number of promising complement therapies has elected to only pursue indications in very rare diseases leaving lupus out of the mix. Another company that has developed complement therapies recently elected to not pursue further research in inflammatory diseases, thus shelving their complement-related therapies and planned trials in lupus and rheumatoid arthritis. As mentioned above, there are also diseases felt to be more attractive than lupus for development. These include diseases that are known to be primarily or heavily dependent on complement activation. Such diseases include paroxysmal nocturnal hemoglobinuria, macular degeneration, and hemolytic uremic syndrome.

At this time, to my knowledge, there are no trials in progress or that planned to use complement inhibitors to treat lupus. The proposed trials to use these drugs in membranoproliferative disease, in dense deposit renal disease, and in ANCA-positive vasculitis provide hope that a complement-related therapy will be tried in lupus, likely after approval for another indication. New efforts by the not for-profit lupus organizations as well as the NIH to monetarily support trials of drugs that should have activity in lupus may allow partnership with industry to stimulate new trials using complement active agents to treat lupus. Until then, ongoing efforts are needed to more completely understand which 
agents would be most beneficial in lupus while offering the least risk of infection or other complications. Targeting therapies to sites of complement activation rather than systemic inhibition of the complement system, at least at this time, appears to have the best efficacy to side effect ratio.

\section{Compliance with Ethics Guidelines}

\section{Conflict of Interest}

Gary S. Gilkeson has a patent US8,569,225 B2 issued to Alexion thru MUSC, a patent US8,652,475 B2 issued to Alexion thru MUSC, and a patent US8,703,140B2 issued to Alexion through the University of Colorado.

Human and Animal Rights and Informed Consent

This article does not contain any studies with human or animal subjects performed by any of the authors.

\section{References and Recommended Reading}

1. Crow MK. Developments in the clinical understanding of lupus. Arthritis Res Ther. 2009;11(5):245.

2. Barilla-Labarca ML, Toder K, Furie R. Targeting the complement system in systemic lupus erythematosus and other diseases. Clin Immunol. 2013;148(3):31321.

3. Ballanti E, Perricone C, Greco E, Ballanti M, Di Muzio G, Chimenti MS, et al. Complement and autoimmunity. Immunol Res. 2013;56(2-3):477-91.

4. Holers VM. Complement and its receptors: new insights into human disease. Annu Rev Immunol. 2014;32:433-59.

5. Boackle SA, Holers VM. Role of complement in the development of autoimmunity. Curr Dir Autoimmun. 2003;6:154-68.

6. Bryan AR, Wu EY. Complement deficiencies in systemic lupus erythematosus. Curr Allergy Asthma Rep. 2014;14(7):448.

7. Holers VM. Complement deficiency states, disease susceptibility, and infection risk in systemic lupus erythematosus. Arthritis Rheum. 1999;42(10):2023-5.

8. Kari JA, Jalalah SM. C1q nephropathy in two young sisters. Pediatr Nephrol. 2008;23(3):487-90.

9. Fleming SD, Shea-Donohue T, Guthridge JM, Kulik L, Waldschmidt TJ, Gipson MG, et al. Mice deficient in complement receptors 1 and 2 lack a tissue injuryinducing subset of the natural antibody repertoire. J Immunol. 2002;169(4):2126-33.

10. Stetson DB, Ko JS, Heidmann T, Medzhitov R. Trex1 prevents cell-intrinsic initiation of autoimmunity. Cell. 2008;134(4):587-98.
11. Kavanagh D, Spitzer D, Kothari PH, Shaikh A, Liszewski MK, Richards A, et al. New roles for the major human 3 '-5' exonuclease TREX1 in human disease. Cell Cycle. 2008;7(12):1718-25.

12. Hedrich CM, Fiebig B, Hauck FH, Sallmann S, Hahn G, Pfeiffer C, et al. Chilblain lupus erythematosus-a review of literature. Clin Rheumatol. 2008;27(8):94954.

13. Yasutomo K, Horiuchi T, Kagami S, Tsukamoto H, Hashimura C, Urushihara M, et al. Mutation of DNASE1 in people with systemic lupus erythematosus. Nat Genet. 2001;28(4):313-4.

14. Napirei M, Karsunky H, Zevnik B, Stephan H, Mannherz HG, Moroy T. Features of systemic lupus erythematosus in Dnase1-deficient mice. Nat Genet. 2000;25(2):177-81.

15. Lech M, Anders HJ. The pathogenesis of lupus nephritis. J Am Soc Nephrol. 2013;24(9):1357-66.

16. Cook HT. Complement and kidney disease. Curr Opin Nephrol Hypertens. 2013;22(3):295-301.

17. Krishnan MR, Wang C, Marion TN. Anti-DNA autoantibodies initiate experimental lupus nephritis by binding directly to the glomerular basement membrane in mice. Kidney Int. 2012;82(2):184-92.

18. Thurman JM, Holers VM. The central role of the alternative complement pathway in human disease. J Immunol. 2006;176(3):1305-10.

19. Abramson SB, Weissmann G. Complement split products and the pathogenesis of SLE. Hosp Pract. $1988 ; 23(12): 45-56$. 
20. Hopkins P, Belmont HM, Buyon J, Philips M, Weissmann G, Abramson SB. Increased levels of plasma anaphylatoxins in systemic lupus erythematosus predict flares of the disease and may elicit vascular injury in lupus cerebritis. Arthritis Rheum. 1988;31(5):632-41.

21. Abramson S, Belmont HM, Hopkins P, Buyon J, Winchester R, Weissmann G. Complement activation and vascular injury in systemic lupus erythematosus. J Rheumatol Suppl. 1987;14 Suppl 13:43-6.

22. Belmont HM, Hopkins P, Edelson HS, Kaplan HB, Ludewig R, Weissmann G, et al. Complement activation during systemic lupus erythematosus. C3a and C5a anaphylatoxins circulate during exacerbations of disease. Arthritis Rheum. 1986;29(9):1085-9.

23. Nangaku M, Couser WG. Mechanisms of immunedeposit formation and the mediation of immune renal injury. Clin Exp Nephrol. 2005;9(3):183-91.

24. Miwa T, Zhou L, Maldonado MA, Madaio MP, Eisenberg RA, Song WC. Absence of CD59 exacerbates systemic autoimmunity in MRL/lpr mice. J Immunol. 2012;189(11):5434-41.

25. Thurman JM, Ljubanovic D, Royer PA, Kraus DM, Molina H, Barry NP, et al. Altered renal tubular expression of the complement inhibitor Crry permits complement activation after ischemia/reperfusion. J Clin Invest. 2006;116(2):357-68.

26. Thurman JM, Lucia MS, Ljubanovic D, Holers VM. Acute tubular necrosis is characterized by activation of the alternative pathway of complement. Kidney Int. 2005;67(2):524-30.

27. Marshall KM, He S, Zhong Z, Atkinson C, Tomlinson S. Dissecting the complement pathway in hepatic injury and regeneration with a novel protective strategy. J Exp Med. 2014;211(9):1793-805.

28. Alexander JJ, Bao L, Jacob A, Kraus DM, Holers VM, Quigg RJ. Administration of the soluble complement inhibitor, Crry-Ig, reduces inflammation and aquaporin 4 expression in lupus cerebritis. Biochim Biophys Acta. 2003;1639(3):169-76.

29. Sekine H, Kinser TT, Qiao F, Martinez E, Paulling $\mathrm{E}$, Ruiz $\mathrm{P}$, et al. The benefit of targeted and selective inhibition of the alternative complement pathway for modulating autoimmunity and renal disease in MRL/lpr mice. Arthritis Rheum. 2011;63(4):1076-85.

30. Sekine H, Reilly CM, Molano ID, Garnier G, Circolo A, Ruiz P, et al. Complement component C3 is not required for full expression of immune complex glomerulonephritis in MRL/lpr mice. J Immunol. 2001;166(10):6444-51.

31. Atkinson C, Qiao F, Song H, Gilkeson GS, Tomlinson $\mathrm{S}$. Low-dose targeted complement inhibition protects against renal disease and other manifestations of autoimmune disease in MRL/lpr mice. J Immunol. 2008;180(2):1231-8.

32. Coppo R, Peruzzi L, Amore A, Martino S, Vergano L, Lastauka I, et al. Dramatic effects of eculizumab in a child with diffuse proliferative lupus nephritis resistant to conventional therapy. Pediatr Nephrol. 2015;30(1):167-72.

33. Velik-Salchner C, Lederer W, Wiedermann F. Eculizumab and renal transplantation in a patient with catastrophic antiphospholipid syndrome: effect of heparin on complement activation. Lupus. 2011;20(7):772.

34. Elliott MK, Jarmi T, Ruiz P, Xu Y, Holers VM, Gilkeson GS. Effects of complement factor D deficiency on the renal disease of MRL/lpr mice. Kidney Int. 2004;65(1):129-38.

35. Watanabe H, Garnier G, Circolo A, Wetsel RA, Ruiz P, Holers VM, et al. Modulation of renal disease in MRL/ lpr mice genetically deficient in the alternative complement pathway factor B. J Immunol. 2000;164(2):786-94.

36. Ruseva MM, Vernon KA, Lesher AM, Schwaeble WJ, Ali YM, Botto M, et al. Loss of properdin exacerbates C3 glomerulopathy resulting from factor $\mathrm{H}$ deficiency. J Am Soc Nephrol. 2013;24(1):43-52.

37. Dimitrova P, Ivanovska N, Schwaeble W, Gyurkovska $\mathrm{V}$, Stover C. The role of properdin in murine zymosaninduced arthritis. Mol Immunol. 2010;47(7-8):145866.

38. Lambris JD, Holers VM, Ricklin D. Complement therapeutics. New York: Springer; 2013. viii, 320 p. p.

39. Atkinson C, Song H, Lu B, Qiao F, Burns TA, Holers $\mathrm{VM}$, et al. Targeted complement inhibition by C3d recognition ameliorates tissue injury without apparent increase in susceptibility to infection. J Clin Invest. 2005; 115(9):2444-53.

40. Kaplan M. Eculizumab (Alexion). Curr Opin Investig Drugs. 2002;3(7):1017-23.

41. Jacob A, Hack B, Bai T, Brorson JR, Quigg RJ, Alexander JJ. Inhibition of C5a receptor alleviates experimental CNS lupus. J Neuroimmunol. 2010;221(1-2):46-52.

42. Romay-Penabad Z, Carrera Marin AL, Willis R, WestonDavies W, Machin S, Cohen H, et al. Complement C5inhibitor rEV576 (coversin) ameliorates in-vivo effects of antiphospholipid antibodies. Lupus. 2014;23(12):1324-6.

43. Shernan SK, Fitch JC, Nussmeier NA, Chen JC, Rollins SA, Mojcik CF, et al. Impact of pexelizumab, an anti-C5 complement antibody, on total mortality and adverse cardiovascular outcomes in cardiac surgical patients undergoing cardiopulmonary bypass. Ann Thorac Surg. 2004;77(3):942-9. discussion 9-50.

44. Xu YY, Buyantseva LV, Agarwal NS, Olivieri K, Zhi YX, Craig TJ. Update on treatment of hereditary angioedema. Clin Exp Allergy: J Br Soc Allergy Clin Immunol. 2013;43(4):395-405.

45. Rohrer B, Coughlin B, Bandyopadhyay M, Holers VM. Systemic human CR2-targeted complement alternative pathway inhibitor ameliorates mouse laser-induced choroidal neovascularization. J Ocul Pharmacol Ther: Off J Assoc Ocul Pharmacol Ther. 2012;28(4):402-9.

46. Rohrer B, Coughlin B, Kunchithapautham K, Long Q, Tomlinson S, Takahashi K, et al. The alternative pathway is required, but not alone sufficient, for retinal 
pathology in mouse laser-induced choroidal neovascularization. Mol Immunol. 2011;48(6-7):e1-8.

47. Rohrer B, Long Q, Coughlin B, Renner B, Huang Y, Kunchithapautham $\mathrm{K}$, et al. A targeted inhibitor of the complement alternative pathway reduces RPE injury and angiogenesis in models of age-related macular degeneration. Adv Exp Med Biol. 2010;703:137-49.

48. Salmon JE, Girardi G, Holers VM. Complement activation as a mediator of antiphospholipid antibody induced pregnancy loss and thrombosis. Ann Rheum Dis. 2002;61 Suppl 2:ii46-50.

49. Salmon JE, Girardi G, Holers VM. Activation of complement mediates antiphospholipid antibody-induced pregnancy loss. Lupus. 2003;12(7):535-8.
50. Rovin BH, Furie R, Latinis K, Looney RJ, Fervenza FC, Sanchez-Guerrero J, et al. Efficacy and safety of rituximab in patients with active proliferative lupus nephritis: the Lupus Nephritis Assessment with Rituximab study. Arthritis Rheum. 2012;64(4):1215-26.

51. Rovin BH, Parikh SV. Lupus nephritis: the evolving role of novel therapeutics. Am J Kidney Dis: Off J Natl Kidney Found. 2014;63(4):677-90.

52. Kanamaru Y, Pfirsch S, Aloulou M, Vrtovsnik F, Essig $\mathrm{M}$, Loirat $\mathrm{C}$, et al. Inhibitory ITAM signaling by Fc alpha RI-FCR gamma chain controls multiple activating responses and prevents renal inflammation. J Immunol. 2008;180(4):2669-78. 